\title{
Designing a Fresh Food Supply Chain Network: An Application of Nonlinear Programming
}

\author{
Yu-Chung Tsao \\ Department of Industrial Management, National Taiwan University of Science and Technology, No. 43 Section 4, \\ Keelung Road, Da’an District, Taipei 106, Taiwan
}

Correspondence should be addressed to Yu-Chung Tsao; yctsao@mail.ntust.edu.tw

Received 30 July 2013; Accepted 19 November 2013

Academic Editor: Chong Lin

Copyright (C) 2013 Yu-Chung Tsao. This is an open access article distributed under the Creative Commons Attribution License, which permits unrestricted use, distribution, and reproduction in any medium, provided the original work is properly cited.

In today's business environment, many fresh food companies have complex supply networks to distribute their products. For example, agricultural products are distributed through a multiechelon supply chain which includes agricultural association, agricultural produce marketing corporations (APMCs), markets, and so forth. In this paper a fresh produce supply network model is designed to determine the optimal service area for APMCs, the replenishment cycle time of APMCs, and the freshness-keeping effort, while maximizing the total profit. The objective is to address the integrated facility location, inventory allocation, and freshness-keeping effort problems. This paper develops an algorithm to solve the nonlinear problem, provides numerical analysis to illustrate the proposed solution procedure, and discusses the effects of various system parameters on the decisions and total profits. A real case of an agricultural product supply chain in Taiwan is used to verify the model. Results of this study can serve as a reference for business managers and administrators.

\section{Introduction}

The demand and distribution volume of fresh food has increased year by year as consumption levels have increased. In 2009, the total production volume of vegetables reached six hundred million tons in China. Compared with the production volume in 2008, it had increased by 2684 tons. However, the distribution of fresh food products, such as agricultural produce and live seafood, are challenging and risky operations due to the perishable nature of such products. Having a robust distribution system to distribute fresh food products not only reduces the food deterioration but also increases the customer service level.

For food supply chain management, Georgiadis et al. [1] presented a system dynamics-based methodological approach for mapping and analyzing multiechelon food supply chains. Apaiah and Hendrix [2] determined the location of primary production, ingredient processing, product production areas, and modes of transportation for Novel Protein Foods in The Netherlands. Osvald and Stirn [3] developed an algorithm to solve the vehicle routing problem with time windows and time-dependent travel-times for fresh vegetables. Cai et al. [4] determined the retailer's optimal order quantity, level of freshness-keeping effort, selling price, and wholesale prices for fresh produce. Hong et al. [5] discussed a financially viable business model for a Radio Frequency Identification (RFID) application versus a food traceability system. They conducted a case study of RFID implementation in a chain of convenience stores in Taiwan. Wang and Li [6] proposed dynamic product quality evaluation based upon a pricing model for perishable food supply chains. Cai et al. [7] considered a supply chain in which a producer supplies a fresh product through a third-party logistics provider to a distant market, where a distributor purchases and sells it to end customers.

So far, few studies have considered the food supply network design problem, that is, simultaneously determining the integrated location, allocation, and inventory decisions. For supply network design, Shen [8] conducted a complete review of the supply design literature and discussed future research topics. Recently, Park et al. [9] considered a single-sourcing network design problem for a three-level supply chain. 
Nagurney [10] proposed a framework for supply network design and redesign that allows for the determination of the optimal levels of capacity and operational production flows. There are a few research papers on the retail/e-tail business models. For instance, Bretthauer et al. [11] determined the appropriate locations of online sales to minimize the total costs and satisfy in-store and online demand. Tsao and Lu [12] developed a supply network design which considers distance discount and quantity discount for transportation costs. Klibi and Martel [13] studied various modeling approaches to design resilient supply networks for the location-transportation problem under uncertainty. Nasr considered transshipment and safety stock under supply interruption in a production system. The issue of supply network design is popular in this field of research.

Designing an appropriate distribution network for fresh food is important in reducing the logistics cost and satisfying the customer service level. However, none considered the perishable nature of fresh food in the supply network design problem, that is, determining the facility location and inventory allocation decisions simultaneously. Distribution of fresh products falls in the category of cold chains, in which the products are kept at low temperature [4]. Preventing the deterioration of perishable products is therefore an important mission, especially for fresh food products. Investing more resources in preservative efforts by using better packaging, more powerful cooling facilities, or faster modes of transportation helps to keep spoilage to a minimum [14]. However, determining the level of the freshness-keeping effort is an important decision. Determining the best trade-off between costs and benefits is a critical problem for the fresh food supply chain. This paper incorporates the freshness-keeping effort decision into the supply network design model. The model simultaneously determines the optimal location, allocation, inventory, and freshness-keeping effort decisions to maximize the total profit for a fresh food product.

The contributions of this paper to the literature are as follows. First, this is the first supply network design paper to consider fresh food products. In particular, this study considers the freshness-keeping effort decision. Second, this paper uses a continuous approximation method to model the total cost. The proposed solution defines the input data in terms of continuous functions and is capable of formulating these functions for a data set of any size. This is very important for dealing with practical problems. Third, this study presents a solution approach for solving the supply network design problem described above. We also conducted a numerical analysis to discuss the impacts of the changing parameters and provide the management implications. Fourth, in this paper, we applied our procedure to an agricultural product distribution system in Taiwan. We show that the model could be applied in actual practice.

\section{Model Formulation}

In this paper, we considered the supply network design for agricultural products. The model can also be applied to other fresh food products. The network studied in this paper is a multiechelon supply chain with farmers selling goods to farmers' associations. Then farmers' associations sell and transport agricultural products to agricultural produce-marketing corporations (APMCs). The APMCs are located at the third level, help consolidate shipments arriving from farmers' associations, and deliver them to retailers (traditional markets, supermarkets, and hyper markets). The retailers downstream meet the demands of end customers. Goods flow from upper-stream facilities to the downstream facilities (see Figure 1).

The mathematical model in this study is based on the following assumptions.

(1) Demand per unit time for retail store in cluster $i$ is an independent and identically distributed Poisson process with rate $\lambda_{i}$.

(2) Each APMC's service area is close to circular. Service regions have somewhat irregular shapes as opposed to circles, hexagons, or squares in the economics literature. This irregular service area is shown to have little effect on the optimal solution [15]. Moreover, each APMC is located in the center of the service area.

(3) Each retailer is assigned to a particular APMC and served only by that APMC when the retailer is in the APMC's service area.

(4) The perishable rate of the fresh food is decreasing as the freshness-keeping effort increases.

(5) The freshness-keeping effort cost is not only convex but also increasing in the freshness-keeping effort.

This study uses the following notations;

$T$ : joint replenishment cycle time (decision variable);

$A_{i}$ : service area for each APMC in cluster $i$, where $i=$ $1,2, \ldots, N$ (decision variable);

$\tau$ : freshness-keeping effort (decision variable);

Q: ordering quantity;

$\theta$ : perishable rate (or deteriorating rate) of the fresh food, $\theta=\alpha-\beta \tau$, where $\alpha$ and $\beta$ are constants;

$F$ : facility cost of opening each APMC;

$\delta_{i}$ : store density in cluster $i$;

$\xi$ : length of the planning horizon;

$\lambda_{i}$ : demand rate for retail store in cluster $i$;

$C_{f}$ : fixed cost per inbound shipment;

$C_{v}$ : variable cost per item for each inbound shipment;

$C_{T}$ : outbound transportation cost per unit distance per item;

$f_{r}$ : constant that depends on the distance metric and shape of the APMC service region;

$k(\tau)$ : freshness-keeping effort cost per unit item, $k(\tau)=a+b \tau^{2}$, where $a$ and $b$ are constants;

$R$ : ordering cost for APMC;

$h$ : inventory holding cost for APMC; 


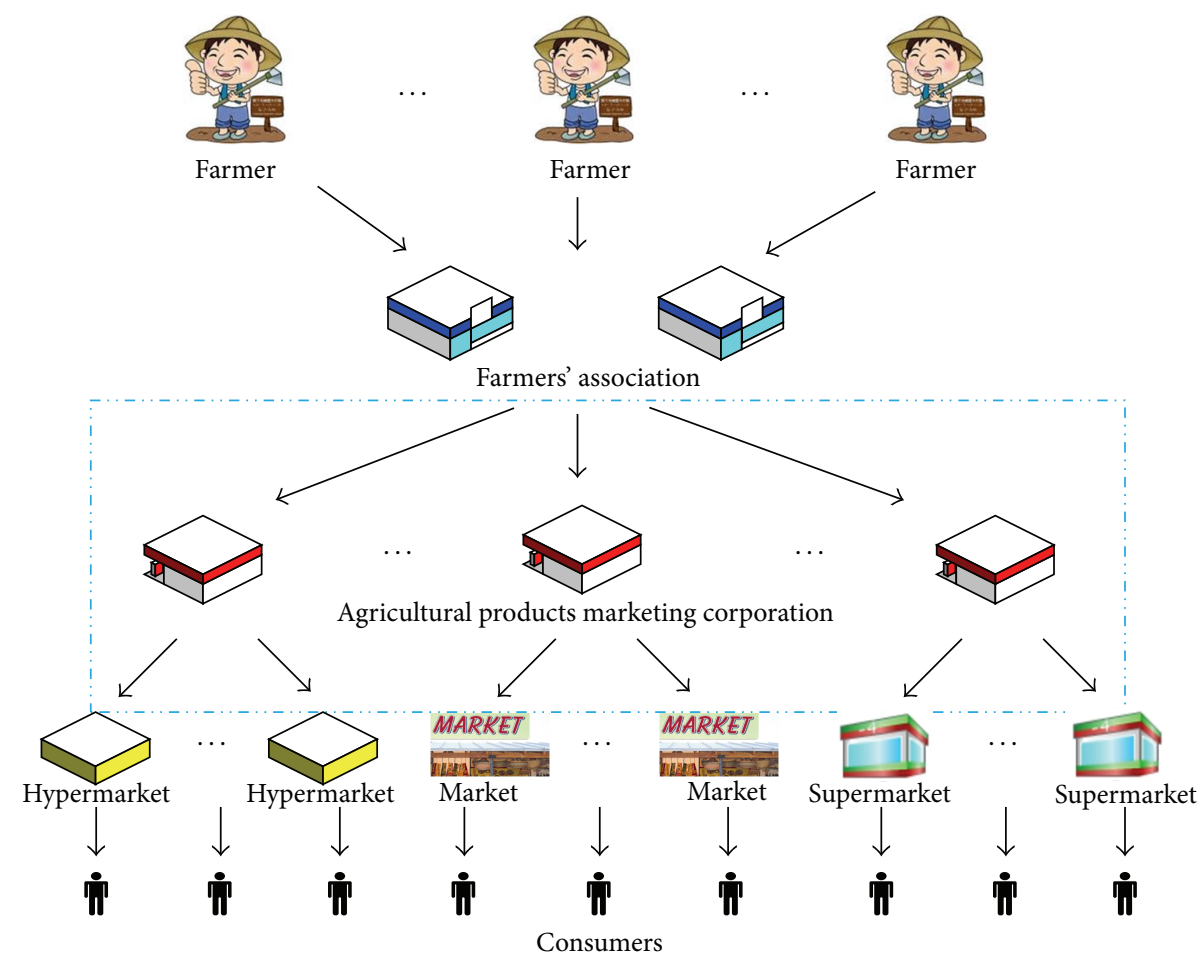

FIGURE 1: Agricultural product supply chain network.

$C_{i}$ : service area in cluster $i$;

$p$ : unit selling price;

$c$ : unit purchasing cost.

This study uses an approximation technique [16] to divide the network into smaller regions over which the discrete variable can be modeled using the slow varying functions. Using the method the given service region is covered with clusters $i, i=1,2, \ldots, N$. Clusters $i, i=1,2, \ldots, N$, exist within the given service region such that the store density is nearly constant over each cluster. This model calculates the components of the total network cost as follows.

(1) The total revenue is $\sum_{i=1}^{N} p \xi \lambda_{i} \delta_{i} C_{i}$.

(2) The total purchasing cost is $\sum_{i=1}^{N} c \xi \lambda_{i} \delta_{i} C_{i}$.

(3) The total facility cost is given by multiplying the facility cost of opening each APMC with the number of APMC s, namely, $\sum_{i=1}^{N} F\left(C_{i} / A_{i}\right)$.

(4) Let $C_{f}$ be the fixed cost per inbound shipment and $C_{v}$ the variable cost per item for each inbound shipment. Then the total inbound transportation cost is $\sum_{i=1}^{N}\left(C_{f}+C_{v} Q\right) / T$.

(5) Assuming "close to circular" service regions with the facility at the center, the average distance traveled by each item is $f_{r} \sqrt{A_{i}}$ [15]. The total outbound transportation cost is $\sum_{i=1}^{N} c_{T} f_{r} \sqrt{A_{i}} \xi \lambda_{i} \delta_{i} C_{i}$.
(6) The total cost for freshness-keeping effort is $\sum_{i=1}^{N}(a+$ $\left.b \tau^{2}\right) \xi \lambda_{i} \delta_{i} C_{i}$

(7) The total ordering cost is $\sum_{i=1}^{N}(R / T)\left(C_{i} / A_{i}\right)$.

(8) Depletion of inventory can occur both as a result of demand and due to deterioration during the replenishment cycle. Variations in the inventory level $I(t)$ with respect to time $t$ can be expressed as

$$
\frac{d I(t)}{d t}=-\theta I(t)-\xi \lambda_{i} \delta_{i} C_{i}, \quad 0 \leq t \leq T,
$$

with the boundary condition $I(T)=0$. The solution to (1) can now be expressed as

$$
I(t)=\frac{\xi \lambda_{i} \delta_{i} C_{i}}{\theta}\left[e^{\theta(T-t)}-1\right], \quad 0 \leq t \leq T
$$

Note that the quantity ordered during each replenishment cycle is

$Q=\frac{\xi \lambda_{i} \delta_{i} C_{i}}{\theta}\left(e^{\theta T}-1\right)=\frac{\xi \lambda_{i} \delta_{i} C_{i}}{\alpha-\beta \tau}\left[e^{(\alpha-\beta \tau) T}-1\right]$

The total inventory holding cost is $\sum_{i=1}^{N}(h / T) \int_{0}^{T} I(t) d t=$ $\sum_{i=1}^{N}\left(h \xi \lambda_{i} \delta_{i} C_{i} / \theta T\right) \int_{0}^{T}\left[e^{\theta(T-t)}-1\right] d t=\sum_{i=1}^{N}\left(h \xi \lambda_{i} \delta_{i} C_{i} /(\alpha-\right.$ $\left.\beta \tau)^{2} T\right)\left[e^{(\alpha-\beta \tau) T}-(\alpha-\beta \tau) T-1\right]$. 
Therefore, the total network profit is

$$
\begin{aligned}
\Pi\left(A_{1}, A_{2}, \ldots, A_{N}, T, \tau\right) \\
=\sum_{i=1}^{N}(p-c) \xi \lambda_{i} \delta_{i} C_{i}-\sum_{i=1}^{N} F \frac{C_{i}}{A_{i}} \\
\quad+\sum_{i=1}^{N} c_{T} f_{r} \sqrt{A_{i}} \xi \lambda_{i} \delta_{i} C_{i} \\
\quad-\sum_{i=1}^{N} \frac{\left\{C_{f}+C_{v} \xi \lambda_{i} \delta_{i} C_{i}\left[e^{(\alpha-\beta \tau) T}-1\right] /(\alpha-\beta \tau)\right\}}{T} \\
\quad-\sum_{i=1}^{N}\left(a+b \tau^{2}\right) \xi \lambda_{i} \delta_{i} C_{i}-\sum_{i=1}^{N} \frac{R}{T} \frac{C_{i}}{A_{i}} \\
\quad-\sum_{i=1}^{N} \frac{h \xi \lambda_{i} \delta_{i} C_{i}}{(\alpha-\beta \tau)^{2} T}\left[e^{(\alpha-\beta \tau) T}-(\alpha-\beta \tau) T-1\right] .
\end{aligned}
$$

\section{Decision-Making Approach}

By using a truncated Taylor series expansion $\left(e^{\lambda T} \approx 1+\lambda T+\right.$ $\left.(1 / 2) \lambda^{2} T^{2}\right)$, we can rewrite (4) as follows:

$$
\begin{aligned}
\Pi\left(A_{1}, A_{2}, \ldots, A_{N}, T, \tau\right) \\
\approx \sum_{i=1}^{N}(p-c) \xi \lambda_{i} \delta_{i} C_{i}-\sum_{i=1}^{N} F \frac{C_{i}}{A_{i}} \\
\quad+\sum_{i=1}^{N} c_{T} f_{r} \sqrt{A_{i}} \xi \lambda_{i} \delta_{i} C_{i} \\
\quad-\sum_{i=1}^{N}\left\{\frac{C_{f}}{T}+C_{v} \xi \lambda_{i} \delta_{i} C_{i}\left[1+\frac{(\alpha-\beta \tau) T}{2}\right]\right\} \\
\quad-\sum_{i=1}^{N}\left(a+b \tau^{2}\right) \xi \lambda_{i} \delta_{i} C_{i}-\sum_{i=1}^{N} \frac{R}{T} \frac{C_{i}}{A_{i}} \\
\quad-\sum_{i=1}^{N} \frac{h \xi \lambda_{i} \delta_{i} C_{i} T}{2} .
\end{aligned}
$$

The problem is to determine the optimal service area, replenishment cycle time, and freshness-keeping effort to maximize the profit function in (5):

$$
\begin{aligned}
\frac{\partial^{2} \Pi}{\partial A_{i}^{2}}= & -\left(\frac{2 F C_{i}}{A_{i}^{3}}\right)-\left(\frac{2 R C_{i}}{T A_{i}^{3}}\right) \\
& -\left(\frac{-c_{T} f_{r} \xi \lambda_{i} \delta_{i} C_{i}}{4 A_{i}^{3 / 2}}\right), \quad i=1,2, \ldots, N . \\
\frac{\partial^{2} \Pi}{\partial \tau^{2}}= & -\sum_{i=1}^{N} 2 b \xi \lambda_{i} \delta_{i} C_{i}<0 .
\end{aligned}
$$

Since the facility opening cost $F$ is large, $\partial^{2} \Pi / \partial A_{i}^{2}<0$ is satisfied in general case. Then from $\partial^{2} \Pi / \partial A_{i} \partial \tau=0$ and $\partial^{2} \Pi / \partial A_{i} \partial A_{k}=0, i=1,2, \ldots, N, k=1,2, \ldots, N, i \neq k$, the Hessian matrix is

$$
H_{N+1}=\left[\begin{array}{ccccccc}
\frac{\partial^{2} \Pi}{\partial A_{1}^{2}} & 0 & . & . & 0 & 0 \\
0 & \frac{\partial^{2} \Pi}{\partial A_{2}^{2}} & \cdot & & & . & 0 \\
\cdot & \cdot & . & & . & . \\
\cdot & & . & . & . & . \\
\cdot & & . & . & . & . \\
0 & . & . & . & 0 & \frac{\partial^{2} \Pi}{\partial A_{N}^{2}} & 0 \\
0 & 0 & . & . & 0 & \frac{\partial^{2} \Pi}{\partial \tau^{2}}
\end{array}\right] .
$$

Since $\partial^{2} \Pi / \partial A_{i}^{2}<0$ and $\partial^{2} \Pi / \partial \tau^{2}<0$ for $i=1,2, \ldots, N$, we know that $(-1)^{j} \cdot\left|D_{j}\right|>0$ is satisfied for all $j, j=$ $1,2, \ldots, N+1$. From the maximum theorem Winston [17], we know that $\Pi\left(A_{1}, A_{2}, \ldots, A_{N}, \tau \mid T\right)$ is a concave function of $\left(A_{1}, A_{2}, \ldots, A_{N}, \tau\right)$. This means that the optimal $A_{i}(T)$ and $\tau(T)$ can be obtained by solving $\partial \Pi / \partial A_{i}=0$ and $\partial \Pi / \partial \tau=0$, $i=1,2, \ldots, N$. To solve this problem, we first determine the closed form of the retail price $A_{i}(T)$ and $\tau(T)$ that maximize $\Pi\left(A_{1}, A_{2}, \ldots, A_{N}, \tau \mid T\right)$. Solving $\partial \Pi / \partial A_{i}=0$ and $\partial \Pi / \partial \tau=$ 0 simultaneously leads to

$$
\begin{gathered}
A_{i}^{*}(T)=\left[\frac{2(R+F T)}{C_{T} f_{r} \xi \lambda_{i} \delta_{i} T^{2}}\right]^{2 / 3}, \\
\tau^{*}(T)=\frac{C_{v} \beta T}{4 b} .
\end{gathered}
$$

Equations (8) and (9) leads to Properties 1 and 2.

Property 1. (a) The service area for each APMC $A_{i}$ increases as the joint replenishment cycle time $T$ or the outbound transportation cost $C_{T}$ decreases.

(b) The service area for each APMC $A_{i}$ increases as the facility cost $F$ or the ordering cost $R$ increases.

Property 2. (a) The freshness-keeping effort $\tau$ increases as the joint replenishment cycle time $T$, the perishable rate parameter $\beta$, or the variable inbound shipment cost $C_{v}$ increases.

(b) The freshness-keeping effort $\tau$ increases as the freshness-keeping effort cost parameter $b$ decreases.

Substituting $\tau^{*}(T)$ and $A_{i}^{*}(T), i=1,2, \ldots, N$, into the corresponding $\Pi\left(A_{1}, A_{2}, \ldots, A_{N}, T, \tau\right)$ reduces the model to a single variable function $\Pi(T)$ :

$$
\begin{aligned}
\Pi(T)= & \sum_{i=1}^{N}(p-c) \xi \lambda_{i} \delta_{i} C_{i}-\sum_{i=1}^{N} F C_{i}\left[\frac{C_{T} f_{r} \xi \lambda_{i} \delta_{i} T^{2}}{2(R+F T)}\right]^{2 / 3} \\
& +\sum_{i=1}^{N} c_{T} f_{r}\left[\frac{2(R+F T)}{C_{T} f_{r} \xi \lambda_{i} \delta_{i} T^{2}}\right]^{1 / 3} \xi \lambda_{i} \delta_{i} C_{i}
\end{aligned}
$$


Step 1. Find an initial solution $T_{i=1}$ by inspection.

Step 2. Calculate $\Pi^{\prime}(T)$ and $\Pi^{\prime \prime}(T)$.

Step 3. Let $T_{i+1}=T_{i}-\frac{\Pi^{\prime}(T)}{\Pi^{\prime \prime}(T)}$.

Step 4. If $\left|T_{i+1}-T_{i}\right| \leq \varepsilon$, where $\varepsilon$ is the tolerance error, then go to Step 5; otherwise, let $i=i+1$ and go to Step 3 .

Step 5. Let $T^{*}=T_{i+1}$ and $\Pi^{*}\left(T^{*}\right)=\Pi\left(T_{i+1}\right)$.

Step 6. Determine $A_{i}^{*}\left(T^{*}\right)$ and $\tau^{*}\left(T^{*}\right)$ by (8) and (9) respectively.

Algorithm 1

$$
\begin{aligned}
& -\sum_{i=1}^{N}\left\{\frac{C_{f}}{T}+C_{v} \xi \lambda_{i} \delta_{i} C_{i}\right. \\
& \left.\quad \times\left[1+\left(\alpha-\beta \sum_{i=1}^{N} \frac{C_{v} \xi \lambda_{i} \delta_{i} C_{i} \beta T}{4 b \xi \lambda_{i} \delta_{i} C_{i}}\right) \frac{T}{2}\right]\right\} \\
& -\sum_{i=1}^{N}\left[a+b\left(\sum_{i=1}^{N} \frac{C_{v} \xi \lambda_{i} \delta_{i} C_{i} \beta T}{4 b \xi \lambda_{i} \delta_{i} C_{i}}\right)^{2}\right] \xi \lambda_{i} \delta_{i} C_{i} \\
& -\sum_{i=1}^{N} \frac{R C_{i}}{T}\left[\frac{C_{T} f_{r} \xi \lambda_{i} \delta_{i} T^{2}}{2(R+F T)}\right]^{2 / 3}-\sum_{i=1}^{N} \frac{h \xi \lambda_{i} \delta_{i} C_{i} T}{2} .
\end{aligned}
$$

Based on the discussion above, Algorithm 1 based on Newton's method determines the optimal values for $T^{*}, A_{i}^{*}$, and $\tau^{*}$.

\section{Numerical Study}

This section presents a numerical study to illustrate the proposed solution approach and provide quantitative insights. The goals of the numerical study in this study are as follows:

(1) to illustrate the procedures of the solution approach;

(2) to discuss the effects of the related parameters on decisions and cost.

4.1. Numerical Example. To illustrate the algorithm described above, we applied our procedure to an agricultural product distribution system in Taiwan. Since Taiwan joined the World Trade Organization (WTO), local agriculture has faced greater competition due to the reduction of customs duties and international trade. Therefore, having an efficient agricultural food supply network is important for Taiwan. As shown in Figure 1, farmers sell their agricultural products to agricultural associations. Then the agricultural product is distributed from agricultural associations to agricultural product-marketing corporations (APMCs). The APMCs consolidate shipments arriving from the agricultural associations and deliver them to the retailers (traditional markets, supermarkets, and hypermarkets). We consider three cities: Taipei City, New Taipei City, and Keelung City in northern Taiwan: they are Cluster 1, Cluster 2, and Cluster 3, respectively, in our example. In this case, we wanted to determine the optimal APMC service areas, the optimal number of APMCs in each cluster, the optimal freshness-keeping effort, and the optimal joint replenishment cycle time. In practice, the related parameters can be determined by regression analysis using historical transaction data. Please note that the data used here have been scaled to protect confidentiality. Please also note that the freshness-keeping effort cost just needs to satisfy the requirement. The freshness-keeping effort cost is not only convex but also increasing in the freshnesskeeping effort. One may get other freshness-keeping effort cost form from the regression analysis. However, our model and solution approach can also be used if the freshnesskeeping effort cost satisfies the above requirement.

The parameters of the product are $F=100000 ; p=100$; $c=50 ; C_{1}=10000 ; C_{2}=8000 ; C_{3}=6000 ; h=1 ; R=30$; $C_{T}=10 ; \lambda_{1}=11 ; \lambda_{2}=10 ; \lambda_{3}=9 ; \xi=12 ; \delta_{1}=0.06 ; \delta_{2}=$ $0.05 ; \delta_{3}=0.04 ; f_{r}=0.01 ; C_{f}=1000 ; C_{v}=5 ; \alpha=0.05 ; \beta=$ $0.01 ; a=3 ; b=0.1$. After applying the algorithm in Section 3, the optimal joint replenishment cycle time is $T^{*}=0.2346$, the optimal APMC service area in cluster $C_{1}$ is $A_{1}^{*}=3998.59$, the optimal APMC service area in cluster $C_{2}$ is $A_{2}^{*}=4811.60$, the optimal APMC service area in cluster $C_{3}$ is $A_{3}^{*}=5989.64$, the optimal freshness-keeping effort is $\tau^{*}=0.0293$, and the total network profit is $\Pi^{*}=4853230$. Figure 2 shows the graphic illustrations of $\Pi$ versus different $T$. The algorithm can find the optimal solution in a very short time.

4.2. Numerical Analysis. Several numerical analyses are conducted to gain management insights into the structures of the proposed policies. The following numerical analyses are used to show the effects of $F, h, R, C_{v}, C_{T}, a, b, \alpha$, and $\beta$ on the optimal decisions and the total network profit. The results of Tables 1, 2, and 3 are as follows.

(1) When the facility cost $F$ increases, the optimal joint replenishment cycle time $T^{*}$, the optimal freshnesskeeping effort $\tau^{*}$, and the total network profit $\Pi^{*}$ decrease, but the optimal APMC service area $A_{i}^{*}$ increases. This verifies Property 1 (b). When the facility cost increases, it is reasonable to increase the APMC service area to reduce the number of APMCs opening.

(2) When the inventory holding cost $h$ increases, the optimal joint replenishment cycle time $T^{*}$, the optimal freshness-keeping effort $\tau^{*}$, and the total network 
TABLE 1: Effects of different system parameters.

\begin{tabular}{|c|c|c|c|c|c|c|}
\hline Parameter & $T^{*}$ & $A_{1}^{*}$ & $A_{2}^{*}$ & $A_{3}^{*}$ & $\tau^{*}$ & $\Pi^{*}$ \\
\hline$F=80000$ & 0.2356 & 3446.60 & 4147.37 & 5162.79 & 0.0294 & 4964300 \\
\hline$F=100000$ & 0.2346 & 3998.59 & 4811.60 & 5989.64 & 0.0293 & 4853230 \\
\hline$F=120000$ & 0.2340 & 4514.75 & 5432.70 & 6762.82 & 0.0292 & 4756130 \\
\hline$h=0.25$ & 0.2876 & 3997.96 & 4810.84 & 5988.70 & 0.0360 & 4853460 \\
\hline$h=0.5$ & 0.2346 & 3998.59 & 4811.60 & 5989.64 & 0.0293 & 4853230 \\
\hline$h=0.75$ & 0.2031 & 3999.11 & 4812.23 & 5990.43 & 0.0254 & 484907 \\
\hline$R=20$ & 0.2327 & 3997.47 & 4810.25 & 5987.97 & 0.0291 & 4853460 \\
\hline$R=30$ & 0.2346 & 3998.59 & 4811.60 & 5989.64 & 0.0293 & 4853230 \\
\hline$R=40$ & 0.2365 & 3999.68 & 4812.92 & 5991.29 & 0.0296 & 4853020 \\
\hline$c_{v}=3$ & 0.2519 & 3998.35 & 4811.31 & 5989.29 & 0.0189 & 5161330 \\
\hline$c_{v}=5$ & 0.2346 & 3998.59 & 4811.60 & 5989.64 & 0.0293 & 4853230 \\
\hline$c_{v}=7$ & 0.2205 & 3998.80 & 4811.86 & 5989.97 & 0.0386 & 4545270 \\
\hline$c_{T}=5$ & 0.2325 & 6347.41 & 7637.99 & 9508.04 & 0.0291 & 5427370 \\
\hline$c_{T}=10$ & 0.2346 & 3998.59 & 4811.60 & 5989.64 & 0.0293 & 4853230 \\
\hline$c_{T}=15$ & 0.2364 & 3051.47 & 3671.91 & 4570.92 & 0.0296 & 4371680 \\
\hline
\end{tabular}

TABLE 2: Effects of $a$ and $b$.

\begin{tabular}{|c|c|c|c|}
\hline \multirow{2}{*}{$\mathrm{a}$} & \multicolumn{3}{|c|}{$\mathrm{b}$} \\
\hline & 0.05 & 0.1 & 0.15 \\
\hline \multirow{6}{*}{2} & $T^{*}=0.2349$ & $T^{*}=0.2346$ & $T^{*}=0.2346$ \\
\hline & $A_{1}^{*}=3998.59$ & $A_{1}^{*}=3998.59$ & $A_{1}^{*}=3998.59$ \\
\hline & $A_{2}^{*}=4811.59$ & $A_{2}^{*}=4811.60$ & $A_{2}^{*}=4811.60$ \\
\hline & $A_{3}{ }^{*}=5989.64$ & $A_{3}{ }^{*}=5989.64$ & $A_{3}{ }^{*}=5989.64$ \\
\hline & $\tau^{*}=0.0587$ & $\tau^{*}=0.0293$ & $\tau^{*}=0.0195$ \\
\hline & $\Pi^{*}=5006370$ & $\Pi^{*}=5006350$ & $\Pi^{*}=5006350$ \\
\hline \multirow{6}{*}{3} & $T^{*}=0.2349$ & $T^{*}=0.2346$ & $T^{*}=0.2346$ \\
\hline & $A_{1}^{*}=3998.59$ & $A_{1}^{*}=3998.59$ & $A_{1}^{*}=3998.59$ \\
\hline & $A_{2}^{*}=4811.59$ & $A_{2}^{*}=4811.60$ & $A_{2}^{*}=4811.60$ \\
\hline & $A_{3}^{*}=5989.64$ & $A_{3}^{*}=5989.64$ & $A_{3}^{*}=5989.64$ \\
\hline & $\tau^{*}=0.0587$ & $\tau^{*}=0.0293$ & $\tau^{*}=0.0195$ \\
\hline & $\Pi^{*}=4853250$ & $\Pi^{*}=4853230$ & $\Pi^{*}=4853230$ \\
\hline \multirow{6}{*}{4} & $T^{*}=0.2349$ & $T^{*}=0.2346$ & $T^{*}=0.2346$ \\
\hline & $A_{1}^{*}=3998.59$ & $A_{1}^{*}=3998.59$ & $A_{1}^{*}=3998.59$ \\
\hline & $A_{2}^{*}=4811.59$ & $A_{2}^{*}=4811.60$ & $A_{2}^{*}=4811.60$ \\
\hline & $A_{3}^{*}=5989.64$ & $A_{3}^{*}=5989.64$ & $A_{3}^{*}=5989.64$ \\
\hline & $\tau^{*}=0.0587$ & $\tau^{*}=0.0293$ & $\tau^{*}=0.0195$ \\
\hline & $\Pi^{*}=4700130$ & $\Pi^{*}=4700110$ & $\Pi^{*}=4700110$ \\
\hline
\end{tabular}

profit $\Pi^{*}$ decrease, but the optimal APMC service area $A_{i}^{*}$ increases. It is reasonable that when the inventory holding cost increases, the company will decrease the replenishment cycle time in an effort to lower inventory costs. Also, the freshness-keeping effort can be decreased with a shorter replenishment cycle time. They will also reduce the number of APMCs to hold less inventory as the inventory holding cost increases.
TABLE 3: Effects of $\alpha$ and $\beta$.

\begin{tabular}{|c|c|c|c|}
\hline \multirow{2}{*}{$\alpha$} & \multicolumn{3}{|c|}{$\beta$} \\
\hline & 0.005 & 0.01 & 0.015 \\
\hline \multirow{6}{*}{0.03} & $T^{*}=0.2519$ & $T^{*}=0.2521$ & $T^{*}=0.2525$ \\
\hline & $A_{1}^{*}=3998.35$ & $A_{1}^{*}=3998.35$ & $A_{1}^{*}=3998.35$ \\
\hline & $A_{2}^{*}=4811.32$ & $A_{2}^{*}=4811.31$ & $A_{2}^{*}=4811.31$ \\
\hline & $A_{3}^{*}=5989.29$ & $A_{3}^{*}=5989.29$ & $A_{3}^{*}=5989.28$ \\
\hline & $\tau^{*}=0.0157$ & $\tau^{*}=0.0315$ & $\tau^{*}=0.0473$ \\
\hline & $\Pi^{*}=4855080$ & $\Pi^{*}=4855100$ & $\Pi^{*}=4855110$ \\
\hline \multirow{6}{*}{0.05} & $T^{*}=0.2345$ & $T^{*}=0.2346$ & $T^{*}=0.2349$ \\
\hline & $A_{1}^{*}=3998.59$ & $A_{1}^{*}=3998.59$ & $A_{1}^{*}=3998.58$ \\
\hline & $A_{2}^{*}=4811.60$ & $A_{2}^{*}=4811.60$ & $A_{2}^{*}=4811.59$ \\
\hline & $A_{3}^{*}=5989.64$ & $A_{3}^{*}=5989.64$ & $A_{3}^{*}=5989.63$ \\
\hline & $\tau^{*}=0.0147$ & $\tau^{*}=0.0293$ & $\tau^{*}=0.0440$ \\
\hline & $\Pi^{*}=4853220$ & $\Pi^{*}=4853230$ & $\Pi^{*}=4853250$ \\
\hline \multirow{6}{*}{0.07} & $T^{*}=0.2202$ & $T^{*}=0.2204$ & $T^{*}=0.2206$ \\
\hline & $A_{1}^{*}=3998.81$ & $A_{1}^{*}=3998.81$ & $A_{1}^{*}=3998.80$ \\
\hline & $A_{2}^{*}=4811.86$ & $A_{2}^{*}=4811.86$ & $A_{2}^{*}=4811.86$ \\
\hline & $A_{3}^{*}=5989.97$ & $A_{3}^{*}=5989.97$ & $A_{3}^{*}=5989.97$ \\
\hline & $\tau^{*}=0.0138$ & $\tau^{*}=0.0275$ & $\tau^{*}=0.0414$ \\
\hline & $\Pi^{*}=4851490$ & $\Pi^{*}=4851490$ & $\Pi^{*}=4851510$ \\
\hline
\end{tabular}

(3) When the ordering cost $R$ increases, the optimal joint replenishment cycle time $T^{*}$, the optimal APMC service area $A_{i}^{*}$, and the optimal freshness-keeping effort $\tau^{*}$ all increase, but the total network profit $\Pi^{*}$ decreases. This also verifies Property 1 (b). If the ordering cost increases, it is reasonable that the company will increase the replenishment cycle time to reduce replenishment frequency. The company will also likely decrease the number of APMCs to 


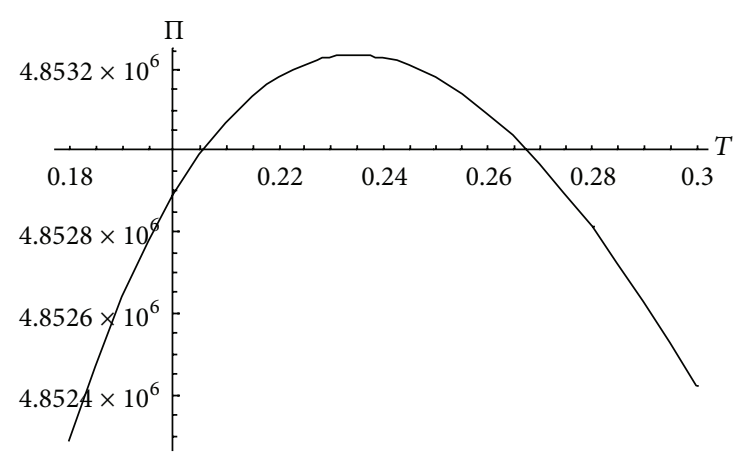

Figure 2: Graphic illustrations of $\Pi$ versus $T$.

reduce the replenishment times as the ordering cost increases.

(4) When the variable inbound shipment cost $C_{v}$ increases, the optimal joint replenishment cycle time $T^{*}$ and the total network profit $\Pi^{*}$ decrease, but the optimal APMC service area $A_{i}^{*}$ and the optimal freshness-keeping effort $\tau^{*}$ increase. This verifies Property 2 (a). The number of APMCs will decrease to reduce the inbound transportation times as the variable inbound shipment cost increases.

(5) When the outbound transportation $\operatorname{cost} C_{T}$ increases, the optimal DC service area $A_{i}^{*}$ and the total network profit $\Pi^{*}$ decrease, but the optimal joint replenishment cycle time $T^{*}$ and the optimal freshness-keeping effort $\tau^{*}$ increase. This also verifies Property 1 (a). When the outbound transportation cost increases, it is reasonable to increase the joint replenishment cycle time to reduce the outbound transportation times.

(6) When the freshness-keeping effort cost increases, the optimal joint replenishment cycle time $T^{*}$, the optimal freshness-keeping effort $\tau^{*}$, and the total network profit $\Pi^{*}$ decrease, but the optimal APMC service area $A_{i}^{*}$ increases. It is reasonable to decrease the freshness-keeping effort and the replenishment cycle time when the freshness-keeping effort cost increases.

(7) When the perishable rate of the fresh food increases, the optimal joint replenishment cycle time $T^{*}$, the optimal freshness-keeping effort $\tau^{*}$, and the total network profit $\Pi^{*}$ decrease, but the optimal APMC service area $A_{i}^{*}$ increases. When the perishable rate of the fresh food increases, the company will decrease the cycle time to reduce the deterioration of the fresh food. When the freshness-keeping effort has more service on reducing the deterioration of the fresh food, companies are willing to increase their freshness-keeping effort.

\section{Conclusions}

This study considers a supply network design problem for agricultural products. The model can also be applied to other fresh food products. The agricultural produce marketing corporations (APMCs) help consolidate shipments arriving from farmers' associations and deliver them to traditional markets, supermarkets, and hypermarkets. The proposed method integrates sales revenue, purchasing costs, facility costs, inventory costs, transportation costs, ordering costs, and freshness-keeping effort costs. The key decisions include where to locate the APMCs, how to assign retailers to APMCs, the joint replenishment cycle time at APMCs, and the freshness-keeping effort, such that the total network profit is maximized. An easy-to-use algorithm is provided for solving the nonlinear programming problem. Numerical studies illustrate the solution procedures and the effects of the facility cost, inventory holding cost, transportation cost, ordering cost, and perishable rate of the fresh food on decisions and profits. The results of this study are a useful reference for managerial decision making and administration. Further research on this topic may consider when the freshness-keeping effort has an influence on demand. This would include the market demand for fresh food dependent on the freshness of the product.

\section{Conflict of Interests}

The author declares that there is no conflict of interests regarding the publication of this paper.

\section{Acknowledgments}

The author expresses his gratitude to the editor and the anonymous reviewers for their detailed comments and valuable suggestions to improve the exposition of this paper. This paper is supported in part by the National Science Council under Grant NSC 102-2410-H-011-029-MY3 and 102-2221-E011-159-MY3.

\section{References}

[1] P. Georgiadis, D. Vlachos, and E. Iakovou, "A system dynamics modeling framework for the strategic supply chain management of food chains," Journal of Food Engineering, vol. 70, no. 3, pp. 351-364, 2005.

[2] R. K. Apaiah and E. M. T. Hendrix, "Design of a supply chain network for pea-based novel protein foods," Journal of Food Engineering, vol. 70, no. 3, pp. 383-391, 2005.

[3] A. Osvald and L. Z. Stirn, "A vehicle routing algorithm for the distribution of fresh vegetables and similar perishable food," Journal of Food Engineering, vol. 85, no. 2, pp. 285-295, 2008.

[4] X. Cai, J. Chen, Y. Xiao, and X. Xu, "Optimization and coordination of fresh product supply chains with freshnesskeeping effort," Production and Operations Management, vol. 19, no. 3, pp. 261-278, 2010.

[5] I.-H. Hong, J.-F. Dang, Y.-H. Tsai et al., "An RFID application in the food supply chain: a case study of convenience stores in Taiwan," Journal of Food Engineering, vol. 106, no. 2, pp. 119-126, 2011.

[6] X. Wang and D. Li, "A dynamic product quality evaluation based pricing model for perishable food supply chains," Omega, vol. 40, no. 6, pp. 906-917, 2012. 
[7] X. Cai, J. Chen, Y. Xiao, X. Xu, and G. Yu, "Fresh-product supply chain management with logistics outsourcing," Omega, vol. 41, no. 4, pp. 752-765, 2013.

[8] Z.-J. M. Shen, "Integrated supply chain design models: a survey and future research directions," Journal of Industrial and Management Optimization, vol. 3, no. 1, pp. 1-27, 2007.

[9] S. Park, T.-E. Lee, and C. S. Sung, "A three-level supply chain network design model with risk-pooling and lead times," Transportation Research E, vol. 46, no. 5, pp. 563-581, 2010.

[10] A. Nagurney, "Optimal supply chain network design and redesign at minimal total cost and with demand satisfaction," International Journal of Production Economics, vol. 128, no. 1, pp. 200-208, 2010.

[11] K. M. Bretthauer, S. Mahar, and M. A. Venakataramanan, "Inventory and distribution strategies for retail/e-tail organizations," Computers and Industrial Engineering, vol. 58, no. 1, pp. 119-132, 2010

[12] Y.-C. Tsao and J.-C. Lu, "A supply chain network design considering transportation cost discounts," Transportation Research E, vol. 48, no. 2, pp. 401-414, 2012.

[13] W. Klibi and A. Martel, "Modeling approaches for the design of resilient supply networks under disruptions," International Journal of Production Economics, vol. 135, no. 2, pp. 882-898, 2012.

[14] S. Doris, "Keeping freshness in fresh-cut product," Agricultural Research, vol. 46, no. 2, pp. 12-14, 1998.

[15] A. Dasci and V. Verter, "A continuous model for productiondistribution system design," European Journal of Operational Research, vol. 129, no. 2, pp. 287-298, 2001.

[16] Y. C. Tsao, D. Mangotra, J. C. Lu, and M. Dong, "A continuous approximation approach for the integrated facility-inventory allocation problem," European Journal of Operational Research, vol. 222, pp. 216-228, 2012.

[17] W. L. Winston, Operations Research Applications and Algorithms, Thomson/Brooks/Cole, Belmont, Mass, USA, 2004. 


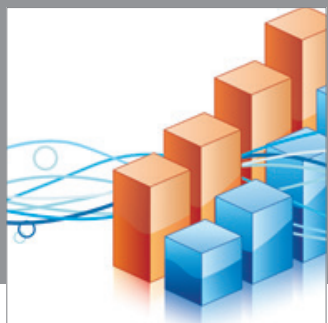

Advances in

Operations Research

mansans

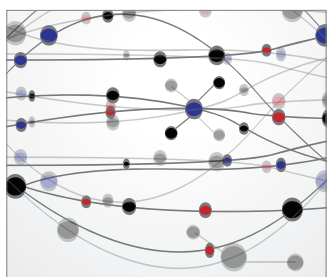

The Scientific World Journal
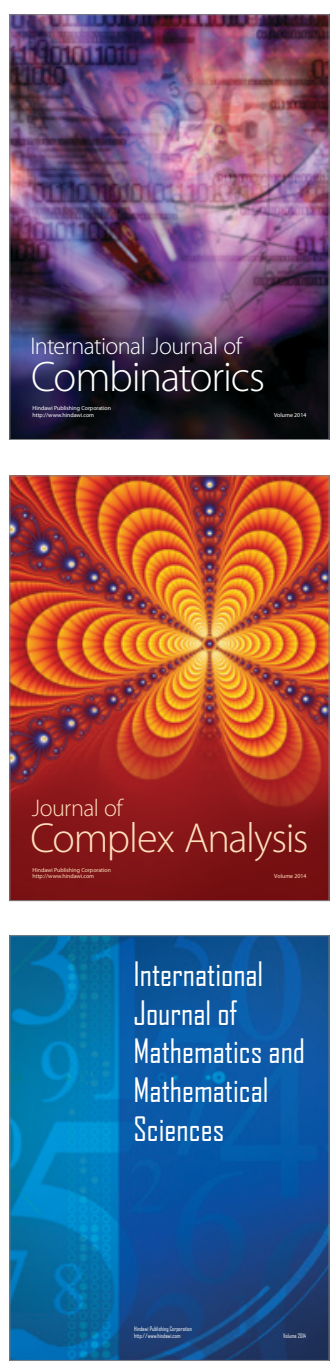
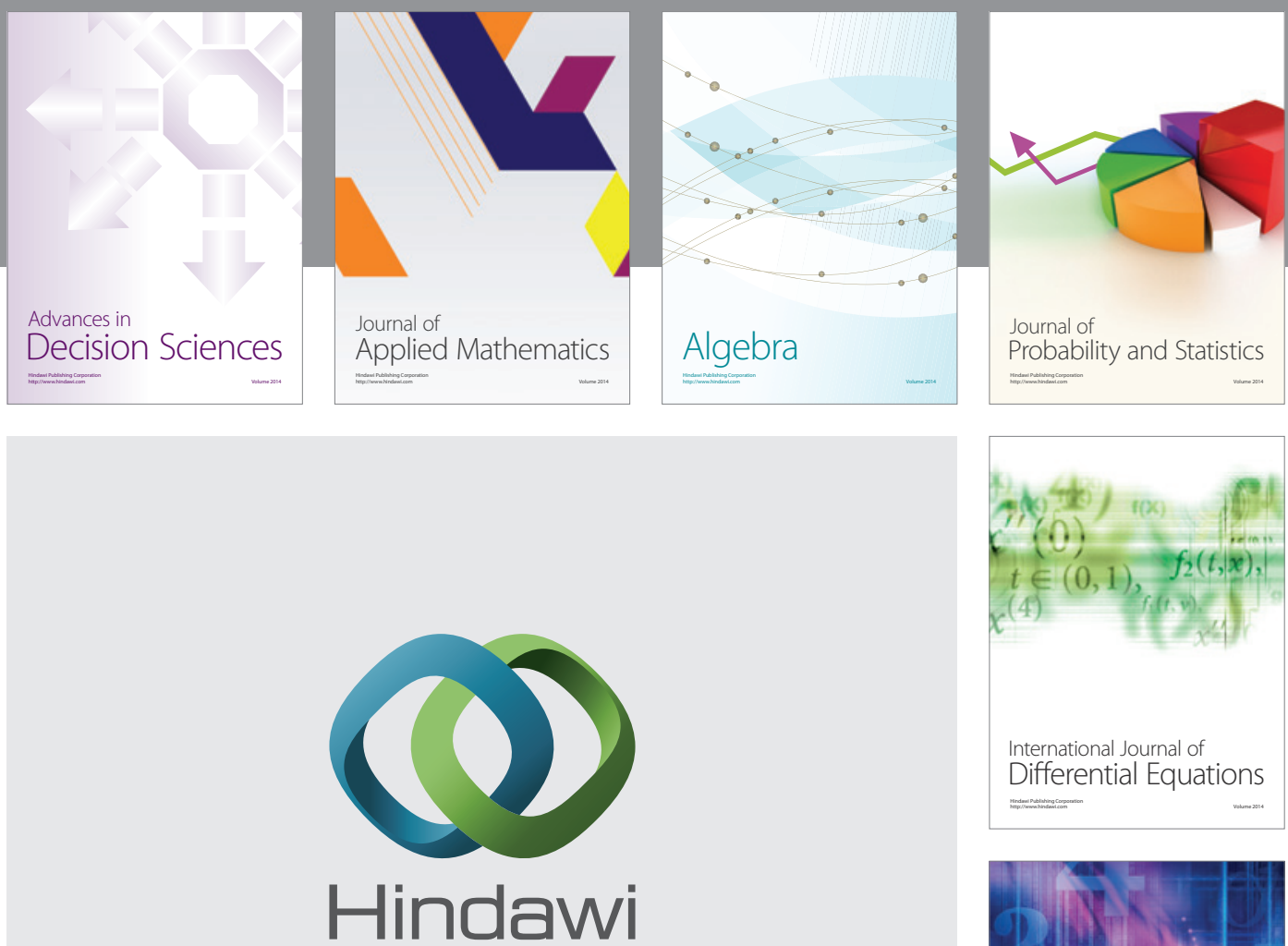

Submit your manuscripts at http://www.hindawi.com
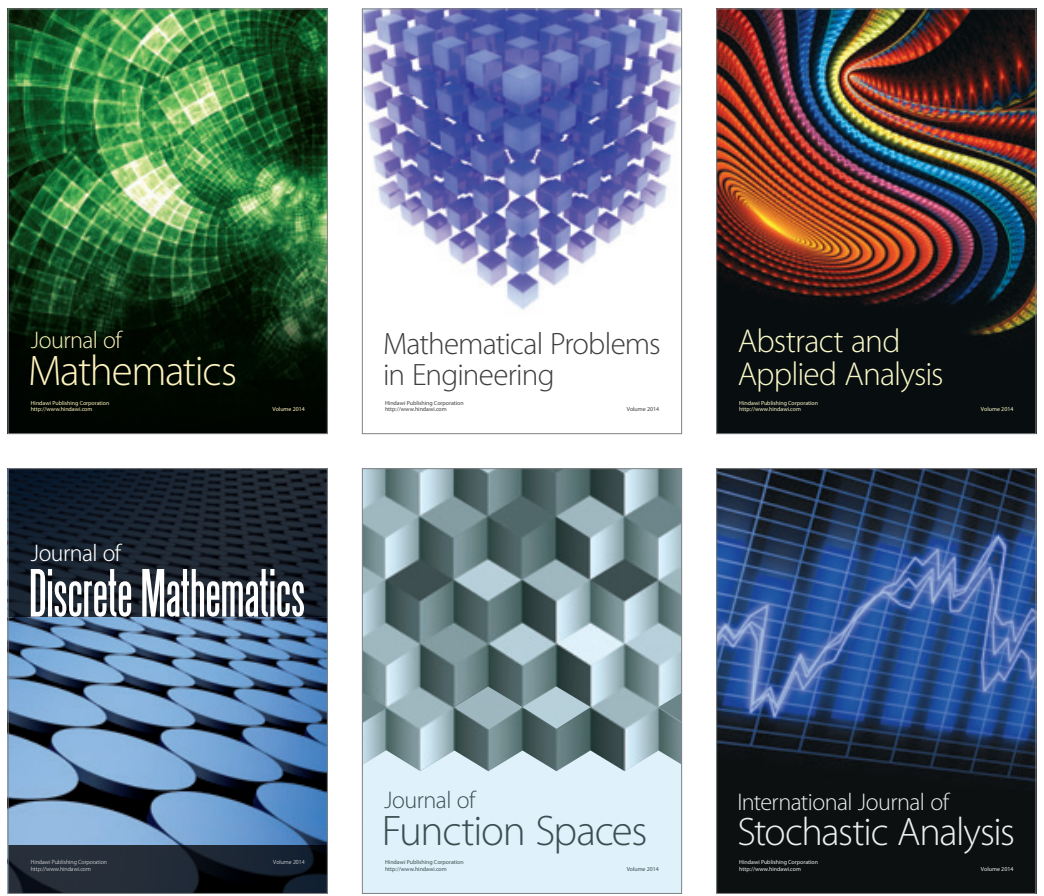

Journal of

Function Spaces

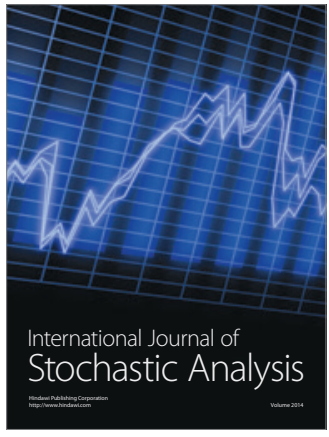

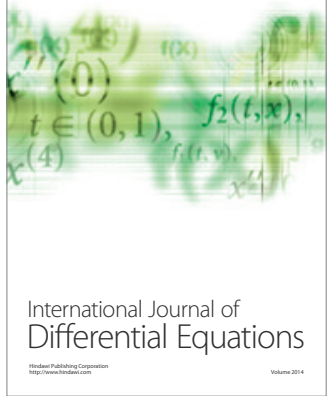
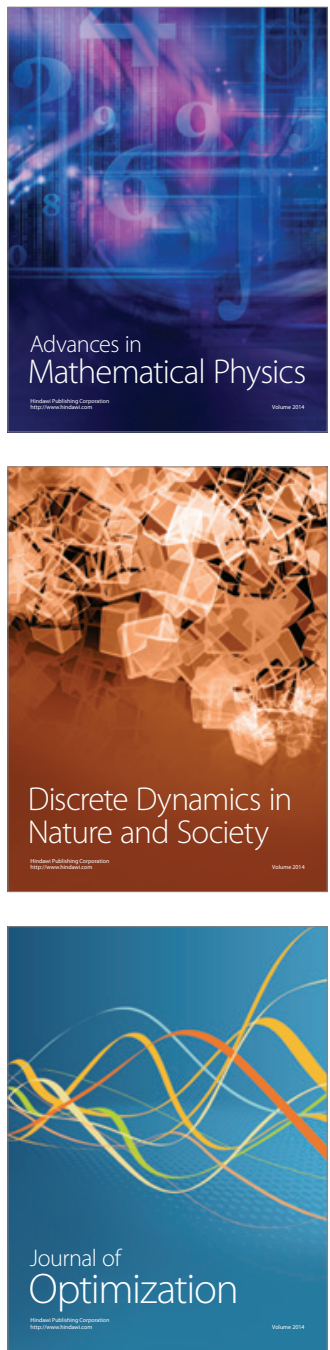